\title{
A BRINCADEIRA DE FAZ DE CONTA COM CRIANÇAS AUTISTAS
}

\author{
MAKE-BELIEVE PLAY WITH AUTISTIC CHILDREN
}

JUEGO IMAGINATIVOS CON NIÑOS AUTISTAS

\author{
José Francisco Chicon*, Ivone Martins de Oliveira*, Rosely da Silva Santos**, \\ Maria das Graças Carvalho Silva de Sá*
}

\begin{abstract}
Palavras chave:
Educação Física.

Transtorno autístico. Jogos e brinquedos. Criança.

Resumo: Este trabalho objetiva compreender como se manifesta a brincadeira de faz de conta com crianças autistas. A metodologia utilizada é o estudo de caso. Os procedimentos metodológicos envolveram intervenções educativas em situações de brincadeira, observações e registros por meio de videogravação e apoio na análise microgenética para a interpretação de episódios de brincadeira de faz de conta. Os sujeitos constam de 17 crianças, de três a seis anos, sendo seis com autismo, uma com síndrome de Down e dez sem deficiência. As crianças foram atendidas em uma brinquedoteca universitária por 13 estagiários do curso de Educação Física, uma vez por semana, durante uma hora, num período de nove meses. As análises indicam que a criança com autismo pode desenvolver o jogo imaginário de forma mais elaborada, desde que lhe sejam ofertadas condições para isso e, nesse processo, o papel mediador do professor é fundamental.
\end{abstract}

\section{Keywords:}

Physical Education.

Autistic disorder.

Play and games.

Children.

Palabras clave: Educación Física. Trastorno autístico. Juegos y juguetes. Niño.

\begin{abstract}
This work aims at understanding how make-believe play is expressed with autistic children. It was a case study and its methodological procedures involved educational interventions during play activities, observation and video recording, and support for micro genetic analysis to interpret make-believe play episodes. Subjects were 17 children aged 3-7, of whom six were autistic, one had Down syndrome, and ten had no disability. The children were seen at the university playroom by 13 student-teachers from the Physical Education School in their practicum, one hour a week, for nine months. The analyses indicate that autistic children are able to develop more elaborate imaginary play as long as they are provided with conditions to do so. Teachers' mediating role is crucial in the process.
\end{abstract}

Resumen: El objetivo de este trabajo es comprender cómo se manifiesta el juego imaginativo con niños autistas. La metodología utilizada es el estudio de caso. Los procedimientos metodológicos implicaron intervenciones educativas en situaciones de juegos, observaciones y registros por medio de videograbación y apoyo en el análisis microgenético para la interpretación del juego. Los participantes fueron 17 niños entre los tres y los seis años, seis de ellos tienen autismo, uno síndrome de Down y diez no tienen ninguna discapacidad. Los niños fueron atendidos en una sala de juegos universitaria por 13 pasantes de la licenciatura de Educación Física, una vez a la semana, durante una hora, en un periodo de nueve meses. Los análisis indican que los niños con autismo pueden desarrollar el juego imaginario de forma más elaborada, siempre que les sean proporcionadas condiciones para ello y, en ese proceso, el papel mediador del profesor es fundamental.
*Universidade Federal do Espírito Santo.Vitória, ES, Brasil. E-mail: chiconjf@yahoo.com.br; imartinsdeoliveira3@gmail.com; mgracasilvasa@gmail.com

**Secretaria Municipal de Educação de Cariacica. Cariacica, ES, Brasil. E-mail: rosy.rodrigs@ hotmail.com

Recebido em: 20-09-2017 Aprovado em: 02-05-2018

DOI: http://dx.doi.org/10.22456/1982-8918.76600 (c) (1) (3) Licence 


\section{INTRODUÇÃO}

O desenvolvimento da brincadeira de faz de conta da criança com autismo ${ }^{1}$ tem se apresentado como um desafio para os profissionais da área educacional, devido não somente às dificuldades de interação social, peculiaridades nos processos comunicativos e interesses restritos, mas também em função da maneira como se apresenta a imaginação nessa criança.

Siegel (2008) destaca que, de modo geral, crianças com autismo apresentam um desenvolvimento mais lento em algumas áreas, como o jogo imaginário. Muitas dessas crianças têm uma relação pouco comum com os brinquedos: algumas parecem não se interessar por eles enquanto outras brincam de maneira não convencional (como cheirar ou passar muito tempo manipulando-os). Frequentemente há uma preferência por algum brinquedo em especial e, diante de outros materiais lúdicos, o interesse é passageiro ou inexistente. Tendendo a "[...] orientarse pelos sentidos, mesmo depois de terem desenvolvido meios mais sofisticados de explorar objetos" (SIEGEL, 2008, p. 87), essas crianças costumam permanecer mais tempo que outras envolvidas em jogos sensoriais: diante de um brinquedo que lhes agrada, elas podem persistirna repetição de um mesmo movimento em relação a esse objeto por vários minutos, entretidas com uma parte específica dele (por exemplo, fazendo girar a roda de uma bicicleta).

Ressalta a autora também que, no jogo desenvolvido por essas crianças, a imaginação nem sempre é evidenciada: "[...] quando brincam com brinquedos, não acrescentam os seus próprios pensamentos, sentimentos ou interpretações ao que viram" (SIEGEL, 2008, p. 89). Numa brincadeira, pode ocorrer de a criança repetir uma sequência de ações próprias de um jogo de maneira puramente imitativa, sem que a imaginação esteja presente, compondo uma brincadeira de faz de conta.

Peculiaridades no jogo imaginário de crianças com autismo também são apontadas nos estudos de Chicon et al. (2016), Chiote (2015), Bagarollo, Ribeiro e Panhoca (2013), Sá, Siquara e Chicon (2015) e Castro, Panhoca e Zanolli (2011), que relatam resultados satisfatórios de pesquisas com intervenção que envolvem atividades lúdicas na ampliação dos processos interativos, da comunicação e da brincadeira dessa criança.

Corroborando pesquisas que ressaltam o valor da brincadeira de faz de conta para o desenvolvimento infantil (VIGOTSKI, 2008; LEONTIEV, 2016), este estudo volta-se para 0 brincar de crianças com autismo e orienta-se pelas seguintes questões: em situações lúdicas em uma brinquedoteca, crianças com autismo brincam de faz de conta? Se brincam, como se manifesta sua brincadeira? Diante dessas questões, este trabalho tem como objetivo compreender como se manifesta a brincadeira de faz de conta em crianças com autismo na brinquedoteca.

\section{A BRINCADEIRA DE FAZ DE CONTA NO APRENDIZADO E DESENVOLVIMENTO INFANTIL}

Ao discorrer sobre a brincadeira na idade pré-escolar, Vigotski (2008) aborda duas questões fundamentais: 0 modo como ela surge na criança e o papel que essa atividade desempenha no desenvolvimento infantil.

1 Compreendemos o autismo como um fenômeno multidisciplinar caracterizado, primordialmente, por um conjunto de sintomas qualitativos que acomete as crianças, em geral, nos 30 primeiros meses de vida, no que tange à sua comunicação social, interatividade e comportamento (SIEGEL, 2008). 
Com relação à origem da brincadeira, o autor destaca que a dificuldade de uma série de teorias em abordá-la diz respeito ao desconhecimento das necessidades e inclinações da criança, seus impulsos e os motivos de sua atividade. Para ele, na origem da brincadeira, entrelaçam-se três processos, a saber: a) o fato de a criança experimentar necessidades que não podem ser satisfeitas no momento; b) a tendência de a criança buscar satisfação imediata das necessidades; c) as transformações operadas na memória que, paulatinamente, propiciam um prolongamento das lembranças das necessidades e desejos não satisfeitos.

Esses processos acabam por provocar uma tensão entre os desejos e suas possibilidades de realização. Mas essa tensão pode ser abrandada por meio da brincadeira que, permitindo uma transformação dos dados da realidade, pode produzir a satisfação desses desejos. Por exemplo: entre o desejo de dirigir um carro e não poder, por meio do imaginário, uma cadeira pode se transformar em um carro, satisfazendo uma necessidade imediata da criança. Entretanto, é importante ressaltar que esse não é um processo consciente e intencional por parte da criança, nem a satisfação de um desejo por meio da brincadeira é imediata. Tratase de um processo complexo e multideterminado.

Assim, um aspecto que merece destaque é que, na brincadeira, a criança cria uma situação imaginária. Para Vigotski (2008) e Leontiev (2016), a brincadeira é parte de um processo de alto nível do desenvolvimento psicológico infantil, na medida em que liberta a criança das amarras situacionais, permitindo-Ihe agir sobre os objetos em uma perspectiva que altera seu uso convencional: há uma "[...] ruptura entre o sentido e o significado de um objeto no brinquedo" (LEONTIEV, 2016, p. 128), a qual emerge no transcorrer da própria brincadeira. Isso pode ser observado de forma nítida na fase pré-escolar (três a seis anos), quando, numa brincadeira, a criança consegue ver além do que o objeto convencionalmente indica, atribuindo-Ihe outros significados, inclusive aqueles que permitem satisfazer suas necessidades, por exemplo: a cadeira que se transforma em um carro. Nesse caso, a ação se submete ao sentido dado pela criança, que "[...] aprende a agir em função do que tem em mente, ou seja, do que está pensando, mas não está visível, apoiando-se nas tendências e nos motivos internos, e não nos motivos e impulsos provenientes das coisas" (VIGOTSKI, 2008, p. 29).

Como condição para a atividade lúdica, encontra-se, ainda, a submissão a determinadas regras. Toda brincadeira implica certas regras, as quais a criança tem de conhecer e respeitar: numa brincadeira de pique-pega, por exemplo, é necessário haver uma criança que corra, para pegar, e outra que corra, para não ser pega. Assim, a criança aprende a orientar sua ação pelas regras que perpassam essa atividade lúdica, sejam implícitas, sejam explícitas; ao brincar ela se autorregula, se autodetermina, se autocontrola.

Diante de todas as transformações que a brincadeira produz nas funções psíquicas, pode-se dizer que ela contribui para a criação de zonas de desenvolvimento iminente ${ }^{2}$, alargando o desenvolvimento potencial da criança e ampliando suas possibilidades de desenvolvimento real (VIGOTSKI, 2007). Por intermédio da brincadeira, aos poucos a criança aprende a ter consciência de suas próprias ações e compreende o ambiente físico e social que a cerca.

2 Concordando com a tradutora deste artigo, Zóia Prestes, contrariando o uso já estabelecido por outras traduções (zona de desenvolvimento proximal ou imediato), mantemos a palavra iminente, porque ela traduz com mais propriedade a ideia de proximidade e possibilidade, ao mesmo tempo. 
Nesse contexto, faz-se necessário evidenciar a importância que a ação mediadora ${ }^{3}$ do professor apresenta para esse processo, na medida em que, ao visualizar aquilo que a criança consegue fazer sozinha, sem ajuda externa, é possível fomentar situações e estratégias do que ela poderá fazer para além do que já faz.

Como essas considerações podem contribuir para a compreensão da brincadeira da criança com autismo? Ao discorrer sobre a lei básica do desenvolvimento, Vigotski (1997, p. 109) afirma que:

Qualquer função psicológica superior no processo de desenvolvimento infantil se manifesta duas vezes, primeiramente como função da conduta coletiva, como a organização da colaboração da criança com as pessoas que a rodeiam; depois, como uma função individual da conduta, como uma capacidade interior da atividade do processo psicológico [...] (tradução nossa).

Considerando que, para o autor, essa lei básica se aplica tanto a crianças sem deficiência quanto àquelas com deficiência, entendemos que assim se realiza com as crianças com autismo e, a partir disso, nosso interesse em investigar a brincadeira dessas crianças.

\section{METODOLOGIA}

Esta pesquisa ${ }^{4}$ trata de um estudo de caso do brincar de crianças com autismo numa brinquedoteca (LÜDKE; ANDRÉ, 2013) que tem uma proposta inclusiva. A investigação ocorreu em uma brinquedoteca universitária que atende crianças com e sem deficiência na faixa etária de três a seis anos, no período de março a dezembro de 2016, perfazendo um total de 24 aulas/ registros.

Participaram do estudo dez crianças de um Centro de Educação Infantil (CEI) com desenvolvimento típico, seis com autismo e uma com síndrome de Down, totalizando 17 participantes. As crianças com autismo e síndrome de Down eram oriundas da comunidade de Vitória/ES. Os atendimentos ocorriam em um encontro semanal de uma hora. As atividades eram coordenadas por 13 estagiários do Curso de Educação Física, que atuavam como professor/ brinquedista ${ }^{5}$ e se dividiam entre as tarefas de ministrar aula, acompanhar individualmente as crianças com autismo e síndrome de Down ${ }^{6}$ e registrar os eventos mais relevantes para a pesquisa por meio de videogravação e fotografia.

Todas as aulas tinham uma sequência de atividades preestabelecidas: acolhimento e conversa inicial, atividade lúdica direcionada, brincadeira livre, arrumação dos brinquedos, roda de conversa e saída. A roda de conversa sobre as atividades previstas e regras de uso dos brinquedos ocorria com as crianças sentadas em círculo, no centro da brinquedoteca. Em seguida, a atividade direcionada seguia um cronograma planejado para todo o grupo durante 0 semestre; de modo geral, a abordagem do conteúdo - aspectos básicos do desenvolvimento

3 Compreendemos o conceito de mediação pedagógica como um processo de intervenção numa relação entre os indivíduos e o mundo da cultura (objetos, pessoas, lugares etc.). Dessa forma a relação deixará de ser direta para ser mediada pelos elementos culturais (OLIVEIRA, 1993).

4 Este estudo é parte de uma pesquisa mais ampla intitulada: "O brincar da criança com autismo na brinquedoteca: inclusão, mediação pedagógica e linguagem", aprovada pelo Comitê de Ética em Pesquisa com seres humanos da Ufes, conforme a Resolução no 466/2012, no dia 21-3-2016, sob o registro CAAE: 52247615.8 .0000 .5542$.

5 Neste estudo, os estagiários foram designados de professores porque exerciam a função docente ao atuarem avaliando, planejando e executando as intervenções com os alunos no espaço da brinquedoteca, e de brinquedistas, por estimular a brincadeira infantil.

6 Para este trabalho, os estagiários orientavam-se por um plano de ensino individualizado, definido por Rodrigues (1991, p. 78), "[...] como o conjunto de estratégias de ensino que visa adaptar o processo de ensino aprendizagem a cada estudante de modo a proporcionar uma compatibilidade face às suas necessidades, interesses e principalmente características individuais". 
do movimento da criança e do brincar - era feita por meio de histórias cujos temas foram os contos de fadas, o folclore brasileiro e a questão da diversidade/diferença (este último tema visando apresentar às crianças não deficientes aquelas com deficiência e incentivá-las a brincar com elas). Depois, as crianças eram deixadas livres para escolher brinquedos e brincadeiras que mais Ihes agradassem. Nesse momento, todos os professores/brinquedistas atuavam como mediadores de diferentes situações iniciadas pelas crianças, individualmente ou em grupos, estimulando e enriquecendo essas atividades ao brincar junto. Terminado 0 tempo destinado à brincadeira livre, as crianças eram incentivadas a guardar os brinquedos e sentar-se em círculo para a roda de conversas sobre as atividades realizadas.

No caso das crianças com autismo, para aquelas que ainda não conseguiam permanecer na roda ou realizar atividades coletivas, buscava-se uma aproximação progressiva dos colegas e o envolvimento com as brincadeiras coletivas; após algumas tentativas, eram deixadas livres para brincar, sempre acompanhadas por um professor/brinquedista, que atuava de modo a incentivar e enriquecer sua brincadeira.

Os instrumentos de coleta de dados foram: observação participante, videogravação das aulas e registros em diário de campo. A organização e o tratamento dos dados foram inspirados na análise microgenética (GÓES, 2000, p. 9), um modo de organização dos dados "...] que requer a atenção a detalhes e o recorte de episódios interativos, sendo o exame orientado para o funcionamento dos sujeitos focais, as relações intersubjetivas e as condições sociais da situação, resultando num relato minucioso dos acontecimentos".

Para compreender como se manifesta a brincadeira de faz de conta em crianças com autismo na brinquedoteca, debruçamo-nos sobre os vídeos das 24 aulas registradas e consultamos as anotações do diário de campo. Desse trabalho, selecionamos cinco episódios considerados por nós representativos de manifestações da brincadeira de faz de conta dessas crianças. Numa segunda etapa, esses episódios foram transcritos, foi feita uma pré-análise do material e selecionado um dos episódios para uma análise mais refinada.

\section{A BRINCADEIRA DE FAZ DE CONTA DA CRIANÇA COM AUTISMO}

$\mathrm{Na}$ análise dos dados, encontramos diferentes episódios de brincadeiras realizadas por duas das crianças com diagnóstico de autismo, reveladoras da presença do jogo imaginário, como também identificamos crianças que, por suas características e peculiaridades, ainda não conseguiam inserir-se nesse tipo de brincadeira. Assim, considerando o objetivo deste estudo, destacamos para análise um episódio de brincadeira em que o jogo de faz de conta se fez presente na ação da criança com autismo, selecionado por sua riqueza e tempo de envolvimento da criança com a brincadeira (cerca de 30 minutos), participação de crianças não deficientes e forma de intervenção do professor/brinquedista. O episódio ocorreu no playground do Centro de Educação Infantil, um dos espaços de aula utilizados como extensão da brinquedoteca.

O protagonista desse episódio é Bernardo 7 , que tinha na época quatro anos e foi diagnosticado com autismo próximo dos dois anos. Quando chegou à brinquedoteca, em agosto de 2015, apresentou características como: falava pouco; não tomava a iniciativa de se aproximar do outro a não ser quando queria algo; resistia em sentar na roda de conversa inicial da aula; era muito apegado a rotinas e ficava a maior parte do tempo envolvido em uma mesma

7 Os nomes utilizados em referência às crianças e aos professores/brinquedistas são fictícios. 
atividade. Durante todo o período em que esteve na brinquedoteca, esses comportamentos foram foco de intervenção pedagógica e aos poucos foram minimizados.

O episódio selecionado ocorreu em outubro de 2016, quando o aluno já apresentava avanços importantes no desenvolvimento, como: ampliação nas interações com os outros colegas e professores; maior compreensão do que era solicitado; iniciativa para propor brincadeiras; expressão de vontades e desejos. Também realizava brincadeiras: piques; rolar no colchão; pular no trampolim; subir e descer do espaldar; andar na trave de equilíbrio na sala de ginástica.

$\mathrm{Na}$ análise, enfocaremos como se manifesta a brincadeira dessa criança, os possíveis motivos, os participantes envolvidos e a maneira como ela entra no jogo, o tempo de permanência; os objetos envolvidos, bem como o processo de intervenção dos adultos.

\title{
4.1 A iniciativa de brincar de bernardo: explorando a imaginação (parte1)
}

\begin{abstract}
depois de brincar de 'seu lobo pegador', Bernardo, acompanhado pela professora/ brinquedista Janaína e pelo professor Hudson, que desempenhava a função de filmar as aulas, encontrou jogado no pátio um objeto em formato de cacho de uva, utilizado para moldar a areia. 0 menino, ao tomar esse objeto em suas mãos, confere-Ihe um significado diferente de seu uso convencional - ele o transforma em uma 'bomba'. Ele inicia um jogo de faz de conta, utilizando o objeto como se fosse uma bomba, lançando-o contra a professora/brinquedista e produzindo 0 som correspondente ao estouro de uma bomba: 'Bum!'. Janaína, por sua vez, não compreendeu de imediato a intenção do menino e não reagiu à situação conforme o esperado. Logo em seguida, Bernardo pega o objeto do chão e o coloca entre as pernas de Janaína, momento no qual ela percebe a proposta da brincadeira e entra no jogo. Na sequência, ela acrescenta algo novo à situação, orientando Bernardo a contar até três, utilizando os dedos como referência e explicando que só então a 'bomba' poderia explodir, indicando a palavra 'Kabum!'. Nesse momento, Janaína organiza uma regra de conduta na ação do menino por meio de uma contagem antes que a bomba venha a explodir. Bernardo acompanha a orientação de Janaína com atenção e repete a contagem com os dedos, terminando com a palavra 'Tibum!'. Nesse momento, a professora/brinquedista reage com expressão de susto, jogando-se no chão, simulando o resultado de uma explosão. Bernardo abre um grande sorriso, demonstrando satisfação com 0 desfecho do jogo. Ele repete essas ações por mais duas vezes, indicando ter internalizado a regra combinada (Gravação em vídeo: 13-10-2016).
\end{abstract}

Nesse primeiro momento do episódio, em que Bernardo transforma o objeto de modelar a areia em uma "bomba", é importante discutir, logo de início, sobre os possíveis motivos que o levam a brincar de explodir pessoas e coisas. Nossa hipótese está fortemente relacionada com a experiência/contato de Bernardo com o meio social, mais especificamente com a mídia. Buscando confirmação ou não dessa hipótese, conversamos com os pais sobre o episódio e eles informaram que o filho assiste com frequência ao desenho animado Angry Birds ${ }^{8} \mathrm{e}$ vídeos de jogos postados na internet que têm conteúdos relacionados com situações de guerra (com bombardeio, uso de granadas, explosões), demonstrando interesse e entusiasmo nos momentos em que há explosões. Sem entrar no mérito da questão, entendemos que há outros conteúdos nas mídias mais apropriados para a idade da criança, mas esse não é o foco da discussão neste momento e, sim, a brincadeira. 
Dialogando com autores que abordam a brincadeira no universo infantil e a mídia como possibilidade de enriquecimento do acervo cultural da criança, portanto, como fonte de inspiração para dar vazão à sua imaginação no ato de brincar, depreendemos dos estudos realizados por Chicon (2013, p. 147) que "[...] os filmes, desenhos animados e programações infantis transmitidos pela televisão servem para ampliar o repertório de possibilidades da criança na realização de suas brincadeiras", e dos estudos de Brougère (1995, p. 56) que:

A televisão não se opõe à brincadeira, mas alimenta-a, influencia-a, estrutura-a na medida em que a brincadeira não nasceu do nada, mas sim daquilo com o que a criança é confrontada. Reciprocamente, a brincadeira permite à criança apropriarse de certos conteúdos da televisão [e outras mídias].

Com base nos argumentos dos autores citados e com o depoimento dos familiares, é possível inferir que a motivação para a brincadeira foco desta discussão tem origem na experiência de Bernardo com os conteúdos midiáticos.

Enquanto lê e imagina a cena, o leitor deve ter se perguntado se alguém incentivou 0 menino a realizar essa brincadeira ou se foi iniciativa dele, bem como se esse tipo de brincadeira estimula a violência. Essa brincadeira realizada por uma criança de cinco anos e com autismo pode causar estranhamento a quem observa de fora.

Vale destacar que esse jogo surgiu de forma espontânea pelo aluno e foi ampliado e enriquecido pela mediação dos professores/brinquedistas. Entendemos que a brincadeira surge como uma necessidade da criança de representar, por meio da brincadeira de faz de conta, a realidade cultural em que vive, para melhor compreendê-la e/ou lidar com ela (VIGOTSKI, 2008).

Não é prática do grupo de pesquisa organizar atividades que envolvam brincadeiras com uso de armas de brinquedo, mais por razões relacionadas com campanhas promovidas por instituições públicas sobre o desarmamento do que pela crença de que o simples uso desse tipo de brinquedo pode afetar de modo negativo a personalidade da criança. Segundo Kishimoto, em depoimento dado a Chicon (2013) sobre esse assunto, não há nenhum estudo comprovando que a utilização de armas de brinquedo, nas brincadeiras infantis, tenha contribuído para aumentar a violência entre os pares ou para formar delinquentes. Para a autora, as armas de brinquedo, como os outros brinquedos, por exemplo, carrinhos, bonecas, pipas, fantasias etc., são apenas estimulantes da ação lúdica da criança. Essa compreensão encontra apoio nos estudos de Brougère (1995, p. 77-78), quando afirma que:

Sendo uma confrontação com a cultura, a brincadeira é, também, confrontação com a violência do mundo, é um encontro com essa violência em nível simbólico. A criança deve dar sentido não só a isso, como ao resto [...]. A criança tem de conviver com isso. Talvez a brincadeira seja o único meio de suportá-la, assim como as crianças que brincam de guerra entre dois bombardeios [...].

Diante disso, entendemos que a brincadeira com armas de brinquedo, por si só, não representa risco de constituir pessoas violentas, nem de incentivar a violência. Antes disso, ela é a expressão de aspectos da cultura pela criança, tal como ela os elabora no momento - no caso em foco, o jogo retrata, por meio da representação lúdica, aspectos da violência presente no contexto em que vive, por meio de uma linguagem acessível a ela. A vivência desse jogo possibilita à criança compreender essa realidade, elaborar ideias e sentimentos, reduzir tensões, sem maiores consequências para sua constituição como ser humano. Portanto, em 
nosso entendimento, brincadeiras como essa, iniciadas pelo próprio indivíduo, não devem ser reprimidas, para que ele possa experimentar aspectos da cultura em suas diferentes dimensões.

Assim, um aspecto que merece destaque é que, na brincadeira, a criança cria uma situação imaginária. A brincadeira é parte de um processo de alto nível do desenvolvimento psicológico infantil, na medida em que liberta a criança das amarras situacionais, permitindoIhe agir sobre os objetos em uma perspectiva que altera seu uso convencional: há uma ruptura entre o sentido e o significado de um objeto na brincadeira, a qual emerge no transcorrer da própria atividade (VIGOTSKI, 2008; LEONTIEV, 2016).

A partir dessa discussão, um fato a ser ressaltado é a autonomia do Bernardo para iniciar a brincadeira, assim como temos observado progressivamente em outras intervenções. Falkenbach, Diesel e Oliveira (2010) afirmam que essa é uma atitude importante para 0 desenvolvimento da criança e pouco comum entre as que têm autismo. Para esses autores, essa iniciativa contribui para a avaliação da criança, pois está associada à sua segurança, à sua curiosidade e desejo exploratório, ao relacionamento com seus colegas, procurando-os para brincar.

Após pegar o objeto de modelar a areia do chão e manuseá-lo, Bernardo atribui a ele um significado diferente daquele que possui e inicia uma brincadeira transformando-o em um artefato explosivo - uma "bomba". Essa sequência de ações se constitui em um forte indicativo do desenvolvimento das funções psicológicas superiores dessa criança. Ao mudar o significado do objeto no jogo imaginário, Bernardo se desprende das amarras situacionais da realidade e "[...] aprende a agir em função do que tem em mente, ou seja, do que está pensando, mas não está visível, apoiando-se nas tendências e nos motivos internos, e não nos motivos e impulsos provenientes das coisas" (VIGOTSKI, 2008, p. 29), dando seus primeiros passos em direção ao desenvolvimento do pensamento abstrato e generalizante.

Outro aspecto a ser destacado é a regra que sempre está presente no jogo, conforme já discutido neste estudo. Analisando a brincadeira, constatamos a manifestação das regras do comportamento social (implícitas) - observadas, por exemplo, na maneira como o menino maneja o brinquedo/artefato explosivo, lançando-o ou colocando-o no local onde a "bomba" explodirá, numa atitude semelhante à dos próprios personagens do desenho Angry Birds -, e das regras sociais (explícitas) - como aquela combinada com a professora/brinquedista de contar de um a três, demarcando o tempo para a explosão. Apostando no desenvolvimento potencial da criança, a professora/brinquedista atua sobre sua zona de desenvolvimento iminente (VIGOTSKI, 2008), ao acrescentar um novo elemento à brincadeira, que é a contagem. A inclusão dessa nova regra no jogo, marcada pela contagem, orienta a ação da criança, permite-lhe conter a expectativa da explosão e favorece o processo de autocontrole, potencializando sua ação.

Constatamos, de acordo com Vigotski (2008), que, ao brincar, a criança se autocontrola e se autodetermina, e quando as regras são respeitadas em sua efetivação, a brincadeira pode possibilitar uma satisfação bem maior do que o impulso imediato.

$\mathrm{Na}$ descrição da segunda parte do episódio, apontaremos a ação mediadora decisiva da professora/brinquedista para manter o interesse de Bernardo na brincadeira e a participação dos colegas e dos outros adultos no jogo. 


\subsection{A Iniciativa De Brincar De Bernardo: Explorando A Imaginação (Parte 2)}

Na sequência da brincadeira, Bernardo demonstra querer explodir a casinha de tijolo, onde brincavam cinco crianças do CEl. As crianças, apesar de não estarem envolvidas diretamente na brincadeira dele, demonstram estar atentas à sua efetivação, ao sinalizarem para ele, gritando que não era para explodir a casa delas. Bernardo entendeu o enunciado, diminuindo a euforia e mostrando frustração, sem saber o que fazer. Observando a situação, Janaína orienta-o a procurar outro local para colocar a 'bomba', e, em seguida, mostra um tronco de árvore cortado e oco, próximo à casinha. O menino logo se entusiasma novamente, desloca-se com a professora/brinquedista para o local e coloca o brinquedo no tronco da árvore, mas é interrompido por uma das meninas que estava brincando na casinha, que se aproximou e disse com firmeza: 'Aqui é nosso quintal, não pode explodir!'. Ignorando a mensagem da menina, Bernardo conta até três e grita: 'Kabum!', explodindo o tronco. A menina volta contrariada para a casinha, enquanto outra colega sai de lá mostrando indignação com a situação ao dizer: 'Explodiram o nosso quintal!'. Bernardo demonstra ouvir a fala da colega, mas parece não se importar. As meninas voltam para a casinha e continuam com a brincadeira. Na sequência, Janaína incentiva Bernardo a explodir outros objetos no pátio da escola, mantendo vivo seu interesse pela atividade. Após explodir dois outros objetos, uma colega do CEl se interessou pela brincadeira e se aproximou. Estava usando um chapéu de mágico e portando uma varinha mágica, materiais usados na atividade anterior que implicava transformar os colegas em animais. A professora/brinquedista propôs que usassem a varinha para transformar os colegas em bicho. De posse da varinha, Bernardo tocou em Janaína e a transformou em sapo. Ela começou a imitar o sapo, pulando pelo pátio da escola. Em seguida, Bernardo aproxima a 'bomba' do sapo, que começa a correr, fugindo das duas crianças. Quando o sapo se cansou, parou e Bernardo colocou o brinquedo entre seus pés, as crianças contaram até três e 'kabum!' - Janaína, jogou-se no chão, simulando susto com a explosão. As duas crianças comemoram juntas o resultado da ação. Em seguida, a colega deixou a brincadeira e Bernardo foi incentivado por Janaína a colocar a 'bomba' dentro do chapéu. O menino decidiu levar o chapéu até outros professores/brinquedistas, pedindo que o usassem. Assim que colocavam o chapéu na cabeça, ele iniciava a contagem verbal em sincronia com o movimento dos dedos: '1, 2, 3. Kabum!' e os brinquedistas simulavam reação à explosão. Por último, Bernardo entregou o chapéu a uma das professoras/ brinquedistas e começou a contar. No momento da explosão, ela rapidamente tirou o chapéu da cabeça, fingindo que escapou da explosão e abraçou Bernardo, encerrando a brincadeira (Gravação em vídeo: 13-10-2016).

Para além da iniciativa de brincar de Bernardo, já evidenciada, é relevante ressaltar a importância da ação mediadora da professora/brinquedista que o acompanhava, o que permitiu ampliar sua experiência de brincar, ao propor variações na brincadeira: sugerindo outras possibilidades de ação; motivando-o a permanecer por mais tempo na atividade; brincando junto; dando atenção e valorizando suas iniciativas; agregando os colegas e criando novas situações lúdicas, como evidenciamos em diferentes momentos da brincadeira.

Também observamos que algumas crianças do CEl, apesar de não estarem envolvidas diretamente na atividade lúdica junto com Bernardo - estavam brincando na casinha de tijolo e outras com outros brinquedos do pátio - em momentos diferenciados, participaram da brincadeira iniciada por ele, reagindo adequadamente à situação quando foram implicadas, como nos momentos em que Bernardo tentou "explodir" a casinha, depois o tronco da árvore (o quintal da casa) e, mais adiante, na brincadeira envolvendo o chapéu e a varinha mágica. As crianças sem deficiência, por iniciativa própria, entraram e saíram rapidamente da brincadeira, 
voltando para suas atividades de interesse, mas deixando sua contribuição no processo de brincar de Bernardo.

Nessa dinâmica, mais uma vez, destacamos o papel mediador da professora/ brinquedista, incentivando a interação entre as crianças e o compartilhamento do jogo, corroborando o pensamento de Chiote (2015), que chama a atenção para a importância da intervenção dos adultos na relação entre pares durante a brincadeira.

\section{CONSIDERAÇÕES FINAIS}

Nossas análises indicam que a criança com autismo também pode se envolver com brincadeiras de faz de conta, desde que lhe sejam ofertadas condições para isso: quanto mais estimuladas em sua experiência lúdica, na exploração dos mais variados brinquedos, na manifestação das diferentes linguagens, na convivência com a diversidade, na exploração de diferentes espaços e modos de interação, mais significativas serão as possibilidades de essa criança sentir, pensar, agir no/com o meio social onde se encontra e brincar.

Neste trabalho, tomamos como principal sujeito Bernardo, que, durante as aulas, teve avanços importantes: maior repertório de brincadeiras e ampliação do tempo de permanência em uma mesma atividade lúdica; iniciativa em criar brincadeira de faz de conta; interação com os colegas durante o jogo; exploração dos diversos cantinhos da brinquedoteca e de outros espaços e objetos; maior autonomia e segurança na relação com os outros e o meio físico. Os avanços de Bernardo no brincar indicam que não se devem estabelecer limites predefinidos para o desenvolvimento da criança com autismo, especificamente no que se refere à imaginação e à brincadeira.

Esses avanços têm uma íntima relação com as oportunidades de interação com os outros, os brinquedos e brincadeiras que compõem o repertório de um dado contexto histórico e cultural, bem como, e principalmente, com a ação mediadora do adulto. A atuação da professora/brinquedista foi crucial ao planejar e orientar a atividade educativa com a criança, mediando sua relação com as demais, incentivando-a a criar brincadeiras e permanecer no jogo imaginário, bem como apontando formas de enriquecer sua brincadeira.

Portanto, no processo de ensino e aprendizagem, não basta o professor organizar os espaços disponibilizando materiais e objetos e observar as crianças; é necessário definir estratégias de abordagem corporal e de intervenções pedagógicas, para que elas possam criar e recriar as brincadeiras, estabelecer novas interações, combinar movimentos e objetos, descobrir novas formas de ação, alimentando, dessa maneira, a experiência corporal (socioafetiva, cognitiva e psicomotora). A brincadeira torna-se, então, uma possibilidade de desenvolvimento da criança com autismo a partir do investimento dos adultos em seu envolvimento nessa prática social específica da infância. 


\section{REFERÊNCIAS}

BAGAROLLO, Maria Fernanda; RIBEIRO, Vanessa Veis; PANHOCA, Ivone. O brincar de uma criança autista sob a ótica da perspectiva histórico-cultural. Revista Brasileira de Educação Especial, v. 19, n.1, p. 107-120, jan./mar. 2013.

BROUGÈRE, Gilles. Brinquedo e cultura. São Paulo: Cortez, 1995.

CASTRO, Glenda Saccomano; PANHOCA, Ivone; ZANOLLI, Maria de Lurdes. Interação comunicativa em contexto lúdico de duas crianças com síndrome de Down, comportamentos autísticos e privação de estímulos. Psicologia: Reflexão e Crítica, v. 24, n. 4, p. 730-738, 2011.

CHICON, José Francisco. Jogo, mediação pedagógica e inclusão: um mergulho no brincar. 2. ed. Várzea Paulista, SP: Fontoura, 2013.

CHICON, José Francisco et al. Educação Física e inclusão: a mediação pedagógica do professor na brinquedoteca. Movimento, v. 22, n. 1, p. 279-292, jan./mar. 2016.

CHIOTE, Fernanda de Araújo Binatti. A interação entre pares no desenvolvimento do brincar da criança com autismo. In: OLIVEIRA, Ivone Martins de (Org.). Autismo e inclusão escolar: percursos, desafios, possibilidades. Curitiba, PR: CRV, 2015. p. 95-114.

FALKENBACH, Atos Prinz; DIESEL, Daniela; OLIVEIRA, Lidiane Cavalheiro de. O jogo da criança autista nas sessões de psicomotricidade relacional. Revista Brasileira de Ciências do Esporte, v. 31, n. 2, p. 203-214, jan. 2010.

GÓES, Maria Cecília Rafael de. A abordagem microgenética na matriz histórico-cultural: uma perspectiva para o estudo da constituição da subjetividade. Caderno Cedes, v. 20, n. 50, p. 9-25, 2000.

LEONTIEV, Alexis Nikolaevich. Os princípios psicológicos da brincadeira pré-escolar. In: VYGOTSKY, Lev Semenovich; LURIA, Alexander Romanovich; LEONTIEV, Alexis Nikolaevich. Linguagem, desenvolvimento e aprendizagem. 14. ed. São Paulo: Ícone, 2016. p. 119-142.

LÜDKE, Menga; ANDRÉ, Marli E. D. A. Pesquisa em educação: abordagens qualitativas. 2. ed. São Paulo: EPU, 2013.

OLIVEIRA, Marta Kohl de. Vygotsky: aprendizado e desenvolvimento um processo sóciohistórico. São Paulo: Scipione, 1993.

RODRIGUES, David Antônio. Aprendizagem individualizada num grupo de multideficientes. In: RODRIGUES, David Antônio (Org.). Métodos e estratégias em educação especial: antologia de textos. Lisboa: Faculdade de Motricidade Humana, 1991. p. 75-83.

SÁ, Maria das Graças Carvalho Silva de; SIQUARA, Zelinda Orlandi; CHICON, José Francisco. Representação simbólica e linguagem de uma criança com autismo no ato de brincar. Revista Brasileira de Ciências do Esporte, v. 37 n. 4, p. 355-361, out./dez. 2015. Disponível em: < http:// www.sciencedirect.com/science/article/pii/S0101328915000785>. Acesso em: 27 abr. 2016.

SIEGEL, Bryna. 0 mundo da criança com autismo: compreender e tratar perturbações do espectro do autismo. 2. ed. Porto: Porto, 2008.

VIGOTSKI, Lev Semenovich. A formação social da mente. 7. ed. São Paulo: Martins Fontes, 2007. 
VIGOTSKI, Lev Semenovich. Obras escogidas V: fundamentos da defectologia. 5. ed. Madri: Visor, 1997.

VIGOTSKI, Lev Semenovich. A brincadeira e o seu papel no desenvolvimento psíquico da criança. Tradução de Zóia Prestes. Revista Virtual de Gestão de Iniciativas Sociais, n. 8, p. 23-36, jun. 2008.

\section{Apoio:}

Fundo de Amparo à Pesquisa e Inovação do Espírito Santo (FAPES). 